\title{
Origin and Development of the Coronary Arteries
}

\author{
Origen y Desarrollo de las Arterias Coronarias
}

Geraldo de Oliveira Silva-Junior; Sandro Wilson da Silva Miranda \& Carlos Alberto Mandarim-de-Lacerda

SILVA JUNIOR, G. O.; MIRANDA, S. W. S. \& MANDARIM-DE-LACERDA, C. A. Origin and development of the coronary arteries. Int. J. Morphol., 27(3):891-898, 2009.

SUMMARY: The formation of the coronary vasculature is a fundamental event in heart development and involves a series of carefully regulated temporal events that include vasculogenesis and angiogenesis. This review focuses the knowledge concerning the formation of the coronary arteries available so far and some molecular mechanisms involved in this process. Understanding coronary embryogenesis is important for interventions regarding adult cardiovascular diseases as well as those necessary to correct heart congenital defects. The insight of the coronary artery development as a result of ingrowth changed the understanding of several congenital coronary artery variations and anomalies described in gross anatomy.

KEY WORDS: Coronary artery; Embryology; Heart; Angiogenesis; Vasculogenesis.

\section{INTRODUCTION}

The development of the coronary vascular system is an interesting model in developmental biology with major implications for the clinical setting. Although coronary vessel development is a form of vasculogenesis followed by angiogenesis, this system uses several unique developmental processes not observed in the formation of other blood vessels (Wada et al., 2003). In embryos at the stages in which identification of the coronary orifices was variable, the proximal epicardial segments of the left and right coronary arteries are usually already identified, in human as well as in rat embryos. On the other hand, a coronary orifice is never seen in the absence of a proximal coronary artery. At all stages studied (in human embryos from $10 \mathrm{~mm}$ crown-rump length and in rat embryos from $11 \mathrm{~mm}$ crown-rump length) vascular structures are identified in the epicardial covering of the heart. Thus, the theories on proximal coronary artery development are inadequate to explain either these data or the known possible congenital abnormalities of the coronary arteries (Bogers et al., 1988). At the earliest embryonic stages, nonetheless, a coronary circulation does not exist, with the blood flowing through the lumen of the heart tube serving to nourish the endocardium and myocardium. By the beginning of the post-somitic period (third week in humans), as the walls of the developing heart increase in thickness, a dedicated vascular system begins to form over the epicardial surface of the myocardium (Bernanke \& Velkey, 2002) but still not connected to the aorta.

There are two models regarding the physiological development of the embryonic coronary arteries. Some authors mentioned that the coronary arteries develop as a budding or outgrowth of the endothelial aortic sinus running towards the adjacent tissue (outgrowth interpretation of the coronary development) (Dbaly et al., 1968; Rychter \& Ostádal, 1971; Virágh \& Challice, 1981). However, the longheld supposition that coronary veins and arteries were formed by outgrowths from the systemic venous sinus and the aorta, respectively, was argued 20 years ago (Bogers et al., 1989). In their study, Bogers and coworkers demonstrated that the major coronary arteries could be identified in the walls of the aortic sinuses before the emergence of coronary arterial orifices, thus suggesting ingrowth rather than outgrowth of the arterial channels. The roots of the right and left coronary arteries are formed when strands from a peritruncal ring of vascular structures penetrate the aorta at the right and left aortic sinuses of Valsalva (Ando et al., 2004).

Thus, at the end of the vasculogenic period without blood flow, the general pattern of the coronary system is set, 
but significant remodeling of the major vessels and capillary system will take place after connection to the aorta. The joining of the coronary system to the general circulatory system is a complex and understudied developmental process, and whether this movement is directed by a chemotactic event or simply represents the "path of least resistance" is unclear thus far (Wada et al.).

It is fascinating to realize the precision with which the coronary arteries connect to the aorta because they are located at the centre of the aortic valve leaflets. Still, it is interesting to note that when anomalies do occur, they are invariably circumferential and not longitudinal. Elucidating the cellular and molecular regulation of this process is imperative for an understanding of coronary arteries formation (Wada et al.). Thus, the goal of this short review is to examine the latest studies that are providing new insights to the complex process of development of the coronary arteries.

The development of the coronary vessels. The formation of the coronary vasculature involves a series of carefully regulated temporal events that include vasculogenesis, angiogenesis, arteriogenesis and remodeling (Tomanek, 2005). The need for a coronary circulation first occurs in the embryo when the compact portions of the ventricles thicken, increasing the diffusion distance for oxygen from the ventricular lumen. This myocardial growth triggers events that dictate the differentiation and migration of precursor cells of the epicardium (Tomanek \& Zheng, 2002). Vasculogenesis has been described as the de novo generation of blood vessels, whereas angiogenesis can be thought of as the generation of capillaries, veins and arteries from preexisting vessels. The process starts with the delivery of vasculogenic cell types to the surface of the heart after beating has begun (Munoz-Chapuli et al., 2002).

Delivery of a population of cells to an existing organ requires dynamic cellular events, and coordination of cell movement with the precise timing of delivery. Moreover, commitment and differentiation is critical for proper vessel formation and organ development. The mesenchymal precursors of the vascular smooth muscle cells and the adventitial fibroblasts originate from an epithelialmesenchymal transformation of the epicardial mesothelium. Precursors of the coronary endothelium are also epicardiumderived cells (EPDCs); the early EPDCs might be found to have a similar competence to that shown by the recently discovered bipotential vascular progenitor cells, which are able to differentiate into endothelium or smooth muscle depending on their exposure to the vascular endothelial growth factor (VEGF) or the platelet-derived growth
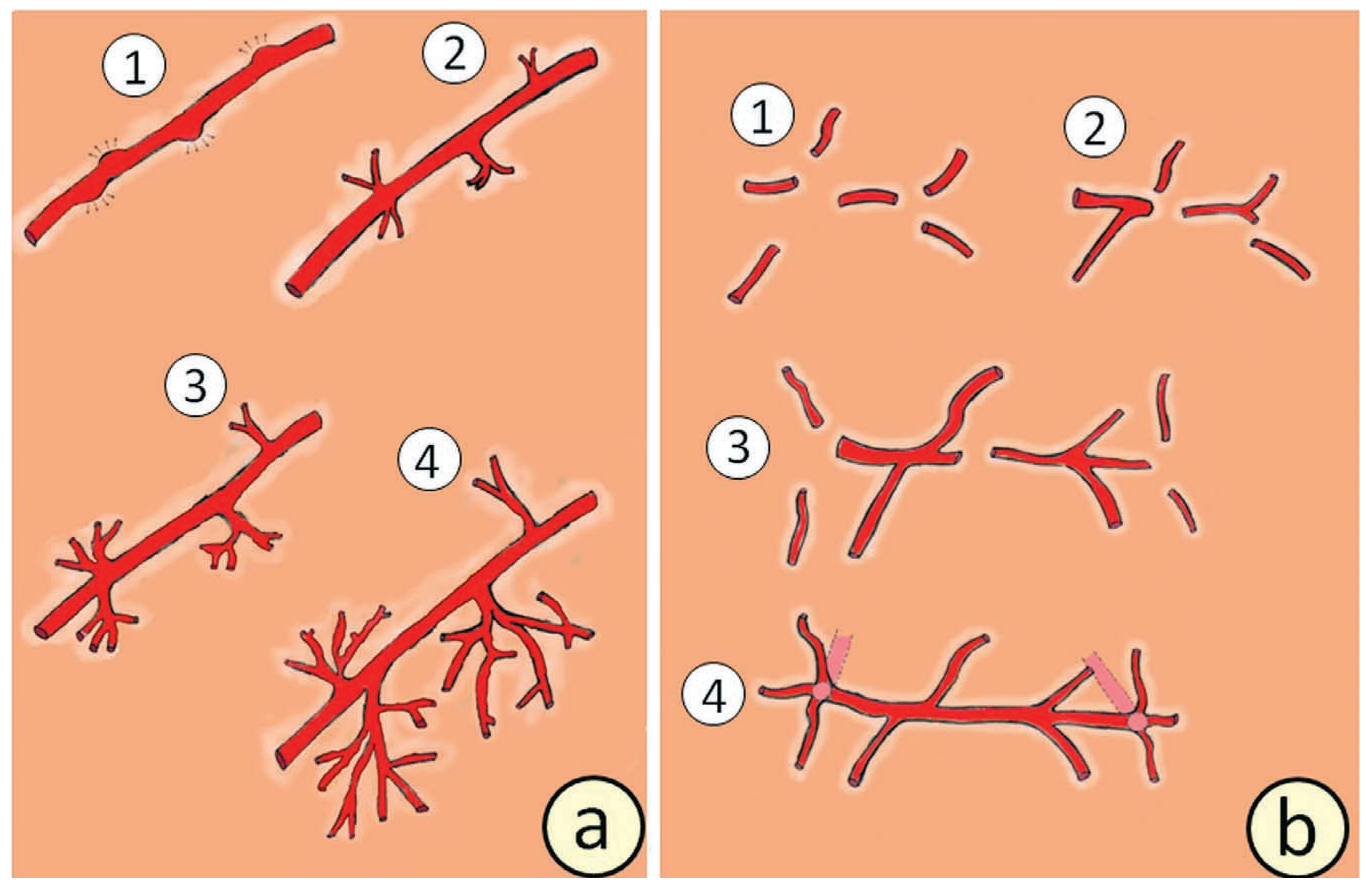

Fig. 1. Angiogenesis and vasculogenesis forming vessels: (A) angiogenesis: it occurs initially with the formation of the budding (1) or endothelial cell outgrowth followed by stretching (2) of small vessels and branching by proliferation (3) of existing endothelial cells and remodeling (4); (B) vasculogenesis: it is the growth of capillaries from pre-existing vessels ( 1 and 2 ), after formation of vascular (capillary) tubes, these undifferentiated vessels fuse forming a continuous vascular structure (3 and 4). 

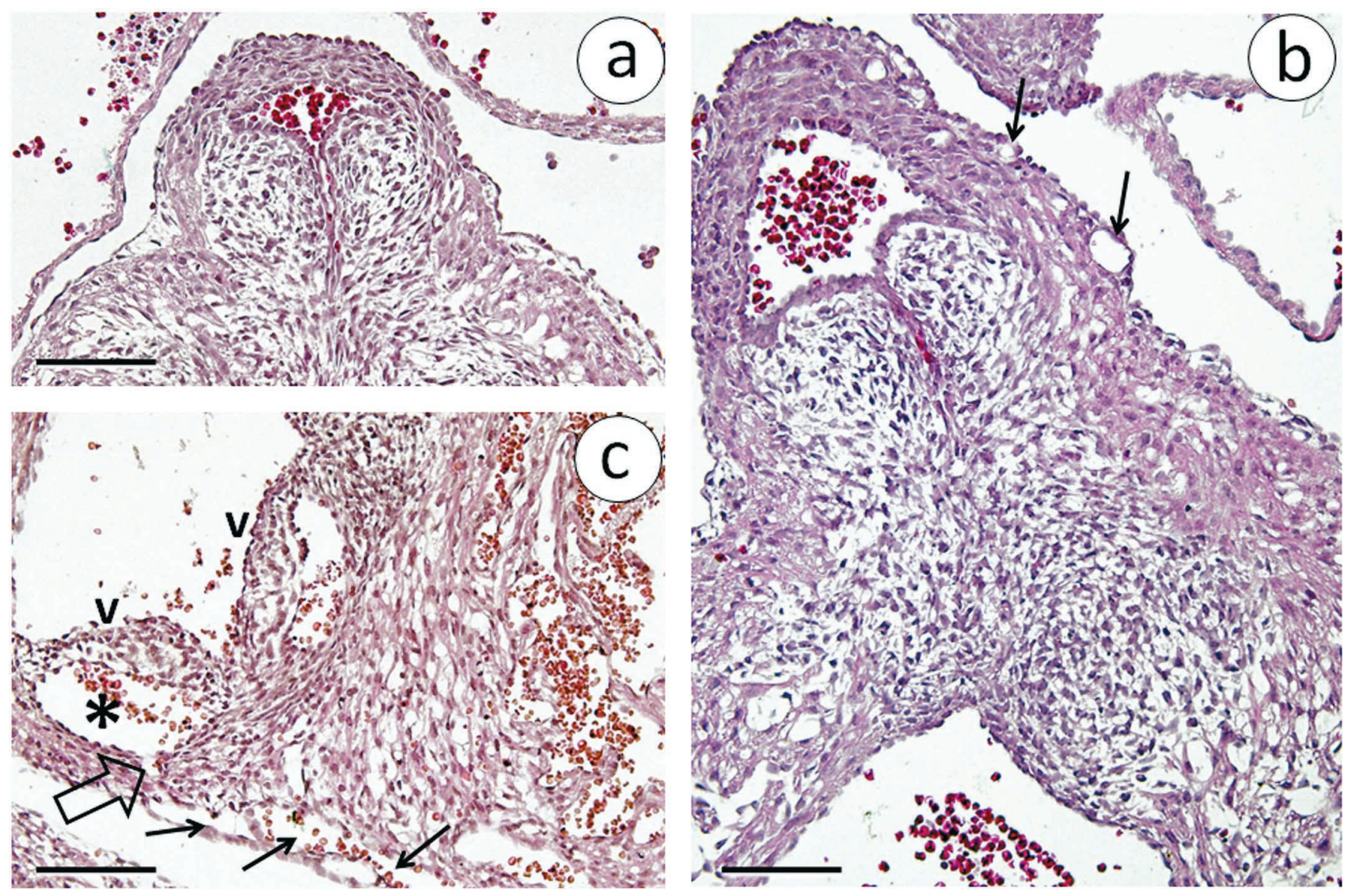

Fig. 2. Photomicrographs of longitudinal histological sections of the aortic valves and ascending aortas of C57BL/6 mice embryos at post somitic period stained with hematoxylin and eosin. (A) Embryo at stage 16 -- staging based on the Carnegie Institute of Washington system (O'Rahilly, 1972), section through the outflow tract and aortic bulb, the subepicardial layer does not show already evident capillaries (scale bar $=100 \mu \mathrm{m})$. (B) Embryo at stage 19, subepicardial capillaries are observed around the aortic bulb $($ arrows $)(\mathrm{scale}$ bar $=75 \mu \mathrm{m})$. (C) Embryo at stage 23, section through the outflow tract and aortic bulb shows the connection between the subepicardial coronary artery (arrows, vessel containing blood cells) and the aortic sinus (of Valsalva, asterisk) through the coronary ostium (open arrow, $\mathrm{v}=$ semilunar valve) (scale bars $=75 \mu \mathrm{m})$.

factor(PDGF)-beta. It is conceivable that the earliest EPDCs differentiate into endothelial cells in response to myocardially secreted VEGF, while subsequent EPDCs, recruited by the nascent capillaries via PDGF-beta signaling, differentiate into pericytes and smooth muscle cells (Munoz-Chapuli et al., 2002). On the other hand, experimental techniques demonstrated the coronary vessel development from its origins in the proepicardium to the final assembled network of arteries, veins, and capillaries present in the mature heart (Dong et al., 2008).The older conception about the origin of the coronary vascular progenitors was derived from the cardiac mesoderm, like the other cell types in the myocardium and endocardium (Patten, 1949; Haan, 1965).

Endothelial cells form vascular (capillary) tubes that fuse and grow in a branching pattern. A capillary plexus makes contact with the coronary sinus and fuses to form a venous connection. Later, the venous system acquires smooth muscle (van den Hoff et al., 2001; Bernanke \& Velkey). As noted in many species, the appearance of capillaries is followed by the development of a venous system prior to the appearance of arterial components of the coronary circulation (Licata, 1954; Hirakow, 1983; Hutchins et al., 1988). The arterial system develops as smooth muscle cells differentiate around the endothelial cells that formed vascular channels (Hood \& Rosenquist, 1992; Mikawa \& Fischman, 1992). The main coronary vessels are formed by a coalescence of small endothelial channels which penetrate the aorta (Bogers et al., 1989; Waldo et al., 1990). Vascular growth is proportional to myocardial growth in the embryonic, overloaded heart, but the persistence of the pressure overload results in a failure or severe limitations in coronary artery development suggesting that vascular growth during this period of development is regulated, at least in part, by the rate and magnitude of myocardial growth (Tomanek et al., 1999). 
Formation of the coronary arteries. The coronary arteries were considered for a long time as mere outgrowths of the aortic root (Dbaly et al.; Rychter \& Ostádal; Virágh \& Challice). In 1989, Bogers and colleagues showed that the major coronary arteries could be seen in the aortic wall prior to the emergence of coronary ostia, thus suggesting an ingrowth rather than outgrowth of these vessels (Bogers et al., 1989). Definitive evidence of this pattern was provided in chick-quail chimeras (Poelmann et al., 1993) and in serially sectioned chick (Waldo et al., 1990) and rat (Tomanek et al., 1996) hearts. The roots of the two main coronary arteries are formed when strands from the peritruncal ring of vascular tubes penetrate the aorta at the left and right cusps (Ando et al.).

Initially, the proximal ends of the coronary arteries migrate toward the proximal aorta. The tips of the advancing coronary vessels must penetrate the tunica media of the aorta, pierce the endothelial lining, and establish continuity with the lumen. Primarily, several coronary vessels approach the left and right aortic sinuses, but only one of these arteries will establish firm contact with each sinus and become the right and left coronary arteries. The mesenchyme of the approaching epicardial vessels meshes with that of the great vessels (Vrancken Peeters et al., 1997; Velkey \& Bernanke, 2001). When connecting coronary vessels approach the endothelium of the aorta, apoptotic cells are found along the aspects of these vessels and their attachment to the aorta (Velkey \& Bernanke).

The formation of the coronary arteries in humans follows a similar pattern to that observed in other mammals and birds. Table I compares the chronological development of the coronary arteries in staged embryos of different species. Penetration of the aorta by the tubular network at the aorta's base is precisely orchestrated so that normally only two major coronary arteries are formed. However, establishment of the coronary ostia is not only spatially, but also temporally, regulated since the left coronary ostium forms prior to the right in both humans and rats (Hirakow; Bogers et al., 1989; Mandarim-de-Lacerda, 1990).

The reasons for confinement of the coronary ostia on two of the three aortic sinuses are still unclear. Microscopic examination of serial sections of human embryos from 5.0 to $17.5 \mathrm{~mm}$ CR length (Carnegie stages 13-19) confirmed that the earliest vessels in the heart wall develop subepicardially near the apex at stage 15 . The network extends centripetally and only at stage 17 could coronary arterial stems, communicating with the aortic lumen, be identified. The sequence suggests that confinement of the coronary ostia to the interior of both the right and left posterior sinuses probably occurs because these represent the most accessible contact points for the centripetally growing vascular plexus (Turner \& Navaratnam, 1996).

Table I. Chronology of coronary artery (CA) development in staged embryos - to mammals, Carnegie Institution of Washington classification (O'Rahilly, 1972); to quail, Hamburger and Hamilton (1992).

\begin{tabular}{llllll}
\hline Author(s) & Species & $\begin{array}{l}\text { Epicardial } \\
\text { Plexus }\end{array}$ & Left CA & Right CA & Both CA \\
\hline Hirakow, 1983 & Human & & Stage 18 (25\% of the & Stage 19 & Stage 19 (40\% of the \\
cases) & & & Sases) \\
Hutchins et al., 1988 & Human & Stages 14 and 15 & & Stage 19 (50\% of the \\
cases)
\end{tabular}




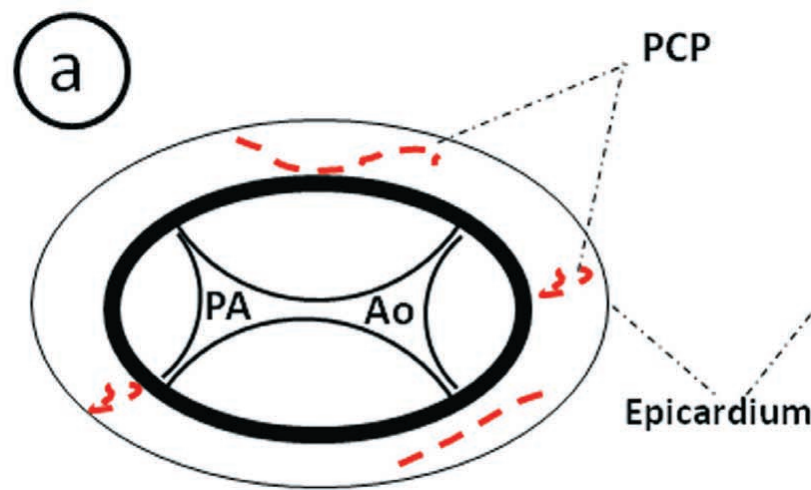

HH 30

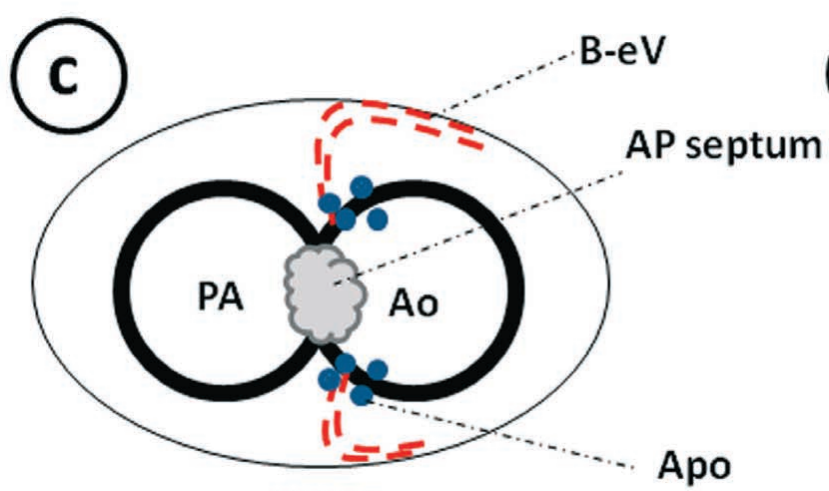

HH 33

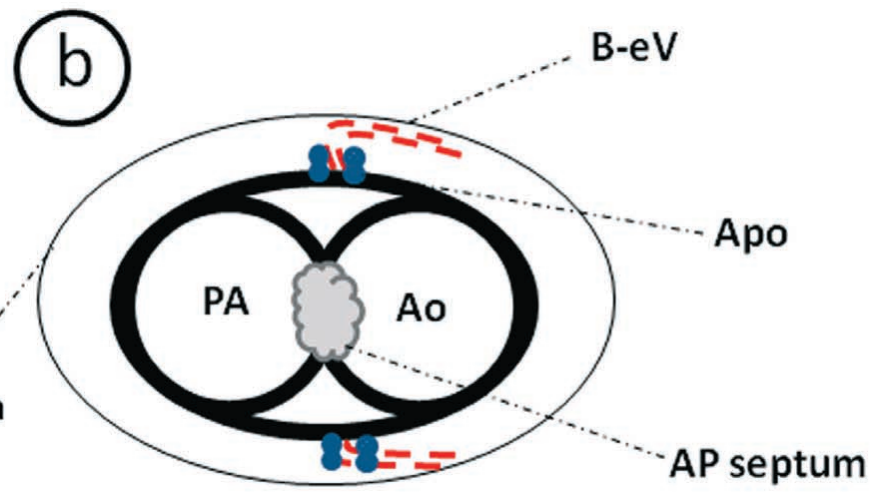

HH 32

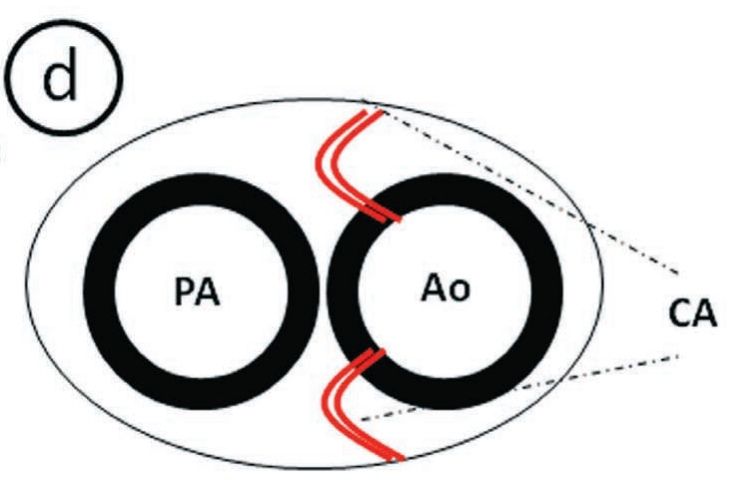

HH 34-35

Fig. 3. The apoptosis in the coronary artery ostia formation: (A) transverse section of the peritruncal region and the developing valves in chicken embryo at stage 30 -- staging based on Hamburger and Hamilton (1992). Peritruncal capillary plexus (PCP) is observed around the aorta (Ao) and pulmonary artery (PA); (B) blind-ended vessels (B-eV) from the PCP penetrate the aortic tissue, apoptotic cells (Apo) are found in association with proliferating vessels of the PCP; (C) once the penetrating vessel reaches the aortic endothelium, the interface between the aortic endothelium and the $\mathrm{B}-\mathrm{eV}$ is transformed into a patent orifice via apoptosis, creating a connection; (D) after connecting the aorta (Ao), some of the penetrating vessels are selected (unknown mechanism) and develop into the definitive proximal coronary arteries (CA).

The developmental proximal part of coronary artery undergoes extensive remodeling as its luminal diameter increases 4-fold between stages 18 and 21 (Ratajska \& Fiejka, 1999). Moreover, experimental evidences suggest that coronary arteriogenesis in the chick provides a structural framework, or conduits, for the differentiation of myocardial cells into Purkinje fibers (Harris et al., 2002).

Some mechanisms are considered reinforcing the theory of "ingrowth" to the development of the coronary arteries. The role of the neural crest cells in the establishment of the main coronary artery stems was indicated (Waldo et al., 1990; Hood \& Rosenquist) as well as transcription factors in the epicardium, eg, Fog-2 (Tevosian et al., 2000) and Ets-1 and Ets-2 (Lie-Venema et al., 2003). The need of VEGF family members for capillary plexus penetration of the aortic root and formation of coronary arteries is also accepted (Tomanek et al., 2006). The unilateral neural crest ablation in the chick resulted in only one contralateral coronary artery main stem which branched to form the right and left. Ectopic origins of a second coronary artery were found in all embryos with neural crest ablation. In the chicken, neural crest cells have been found to disrupt the media of the base of the coronary artery (Waldo et al., 1994) and contribute to parasympathetic ganglia and nerves, present prior to the establishment of coronary arteries (Tomanek).

Role of growth factors in coronary morphogenesis. The mechanisms underlying the specification of this key event are still unknown. One morphological clue noted in the quail is the intense density of transcripts for receptors VEGF receptor-2 (R2) and VEGF receptor-3 (R3) at the sites where the coronaries originate. This is a region where epicardial and subepicardial cells stain more intensely for VEGF (Tomanek et al., 2002). Thus, VEGF and its receptors are critical for the formation of the coronary artery stems (Munoz-Chapuli et al.). 
The hypothesis that this family of growth factors provides the key signaling mechanism for coronary ostia and artery formation were based on the observation of high expression of VEGF in epicardial and subepicardial cells at the aortic root and the high density of VEGF-R2 and -R3 transcripts at the aortic sites of coronary artery roots. VEGF family members are required for the formation of the main coronary arteries via endothelial cell penetration in the aorta because VEGF-Trap prevented this event (Tomanek et al., 2002; Tomanek et al., 2006).

Apoptosis during development of the coronary artery. During the formation of the proximal coronary artery, endothelial strands from the peritruncal ring penetrate the facing sinuses and then fuse, whereas those strands penetrating the noncoronary sinus disappear. Thereafter, the tunica media of the coronary artery demarcates the definitive proximal coronary artery from the aortic tunica media (Ando et al.). A relationship between apoptosis and coronary ingrowth was first reported by Velkey and Bernanke (Velkey \& Bernanke). These authors did not clearly indicate any specific regulatory mechanism acting during coronary artery development. In the absence of any characterization of the apoptotic cells or any experimental manipulation of aortic and coronary vascular tissue, it is difficult to offer a molecular explanation for the complex events involved in coronary artery development. The results only confirm that apoptosis is involved in the formation of the proximal coronary arteries and their orifices. Thus, these findings generate avenues for future research and suggest that factors involved in regulating apoptosis should be included in future models of coronary artery development (Bernanke \& Velkey).
The process of apoptosis in the development of the coronary artery can be didactically divided into three stages: a) invasion, during the process of vascular invasion of the aorta, blind-ended vessels from the peritruncal capillary plexus invade the aortic tissue. Apoptotic cells are found in association with the proliferating vessels of the peritruncal capillary plexus, but not within the aortic endothelium; b) connection, when the invading vessel contacts the aortic endothelium, the interface between the aortic endothelium and the blind end of the vessel is transformed into a patent orifice via apoptosis; $\mathrm{c}$ ) remodeling, after connecting to the aorta, some of the penetrating vessels are selected by an yet unknown mechanism that develops into the definitive proximal coronary arteries. These vessels begin to acquire a vascular smooth muscle coat and increase in diameter. The coronary orifice and the surrounding aortic tissue must accommodate the expansion of the coronary arteries, and it is presumed that apoptosis plays a vital role in this remodeling process (Velkey \& Bernanke, 2001; Rothenberg et al., 2002).

Final remarks. The insight of the coronary artery development as a result of ingrowth changed the understanding of several congenital coronary artery variations and anomalies classically described in gross anatomy. The origin of the coronary arteries outside of the aortic sinuses, e. g. the pulmonary trunk or the pulmonary arteries (Castorina et al., 2008; Farouk et al., 2009), or the extremely high position of the coronary orifices from the ascending aorta (Piegger et al., 2001), are better explained by the ingrowth theory of the origin of the coronary artery. The existence and high prevalence of myocardial bridges on the main branches of the coronary arteries (Mandarim-de-Lacerda et al., 1987; Belov Iu \& Bogopol'skaia, 2004) is also comprehensible in view of the ingrowth theory.

SILVA JUNIOR, G. O.; MIRANDA, S. W. S. \& MANDARIM-DE-LACERDA, C. A. Origen y desarrollo de las arterias coronarias. Int. J. Morphol., 27(3):891-898, 2009.

RESUMEN: La formación de la vascularización coronaria es un acontecimiento fundamental en el desarrollo del corazón e implica una serie de eventos temporales cuidadosamente regulados que incluyen vasculogénesis y angiogénesis. Esta revisión se focaliza en el conocimiento sobre la formación de las arterias coronarias y algunos mecanismos moleculares implicados en este proceso. Entender la embriogénesis coronaria es importante para las intervenciones relacionadas con las enfermedades cardiovasculares en los adultos, así como también, para corregir defectos congénitos del corazón. La idea del desarrollo de la arteria coronaria, como resultado del crecimiento interno, cambió la comprensión de diversas variaciones y anomalías congénitas de estas arterias descritas en la anatomía macroscópica.

PALABRAS CLAVE: Arteria coronaria; Embriología; Corazón; Angiogénesis; Vasculogénesis.

\section{REFERENCES}

Ando, K.; Nakajima, Y.; Yamagishi, T.; Yamamoto, S. \& Nakamura, H. Development of proximal coronary arteries in quail embryonic heart: multiple capillaries penetrating the aortic sinus fuse to form maincoronary trunk. Circ. Res., 94:346-52, 2004.
Belov Iu, V. \& Bogopol'skaia, O. M. Myocardial bridgecongenital anomaly of coronary vasculature. Kardiologiia, 44(12):89-94, 2004.

Bernanke, D. H. \& Velkey, J. M. Development of the 
coronary blood supply: changing concepts and current ideas. Anat. Rec., 269(4):198-208, 2002.

Bogers, A. J.; Gittenberger-de Groot, A. C.; Dubbeldam, J. A. \& Huysmans, H. A. The inadequacy of existing theories on development of the proximal coronary arteries and their connexions with the arterial trunks. Int. J. Cardiol., 20(1):117-23, 1988.

Bogers, A. J.; Gittenberger-de Groot, A. C.; Poelmann, R. E.; Péault, B. M. \& Huysmans, H. A. Development of the origin of the coronary arteries, a matter of ingrowth or outgrowth? Anat. Embryol., 180(5):437-41, 1989.

Castorina, S.; Mignosa, C.; Degno, S.; Bianca, I.; Salvo, D.; Tolaro, S.; Luca, T.; Privitera, G. \& Riccioli, V. Demonstration of an anomalous connection between the left coronary artery and the pulmonary artery using a multislice CT 64. Clin. Anat., 21(4):319-24, 2008.

Dbaly, J.; Os`tádal, B. \& Rychter, Z. Development of the coronary arteries in rat embryos. Acta Anat., 71(2):20922, 1968.

Dong, X. R.; Maguire, C. T.; Wu, S. P. \& Majesky, M. W. Chapter 9. Development of coronary vessels. Methods. Enzymol., 445:209-28, 2008.

Haan, R. L. Development of pacemaker tissue in the embryonic heart. Ann. N. Y. Acad. Sci., 127(1):7-18, 1965.

Farouk, A.; Zahka, K.; Siwik, E.; Golden, A.; Karimi, M.; Uddin, M. \& Hennein, H. A. Anomalous origin of the left coronary artery from the right pulmonary artery. $J$. Card. Surg., 24(1):49-54, 2009.

Hamburger, V. \& Hamilton, H. L. A series of normal stages in the development of the chick embryo. 1951. Dev. Dyn., 195(4):231-72, 1992.

Harris, B. S.; O'Brien, T. X. \& Gourdie, R. G. Coronary arteriogenesis and differentiation of periarterial Purkinje fibers in the chick heart: is there a link? Tex. Heart Inst. J., 29(4):262-70, 2002.

Hirakow, R. Development of the cardiac blood vessels in staged human embryos. Acta Anat., 115(3):220-30, 1983.

Hood, L. C. \& Rosenquist, T. H. Coronary artery development in the chick: origin and deployment of smooth muscle cells, and the effects of neural crest ablation. Anat. Rec., 234(2):291-300, 1992.
Hutchins, G. M.; Kessler-Hanna, A. \& Moore, G. W. Development of the coronary arteries in the embryonic human heart. Circulation, 77:1250-7, 1988.

Licata, R. H. The human embryonic heart in the ninth week. Am. J. Anat., 94(1):73-125, 1954.

Lie-Venema, H.; Gittenberger-de Groot, A. C.; van Empel, L. J.; Boot, M. J.; Kerkdijk, H.; de Kant, E. \& DeRuiter, M. C. Ets-1 and Ets-2 transcription factors are essential for normal coronary and myocardial development in chicken embryos. Circ. Res., 92(7):749-56, 2003.

Mandarim-de-Lacerda, C. A. Development of the coronary arteries in staged human embryos the Paris Embryological Collection revisited. An. Acad. Bras. Cienc., 62(1):79-84, 1990.

Mandarim-de-Lacerda, C. A.; Souza, D. S. \& Bonfim, V. Estudo morfométrico e estatístico da presença de "pontes" miocárdicas sobre o ramo interventricular anterior (descendente anterior) da artéria coronária esquerda em brasileiros. Arq. Bras. Cardiol., 49(1):19-23, 1987.

Mikawa, T. \& Fischman, D. A. Retroviral analysis of cardiac morphogenesis: discontinuous formation of coronary vessels. Proc. Natl. Acad. Sci. USA, 89(20):9504-8, 1992.

Munoz-Chapuli, R.; Gonzalez-Iriarte, M.; Carmona, R.; Atencia, G.; Macias, D. \& Perez-Pomares, J. M. Cellular precursors of the coronary arteries. Tex. Heart Inst. J., 29(4):243-9, 2002.

O'Rahilly, R. Guide to the staging of human embryos. Anat. Anz., 130(5):556-9, 1972.

Patten, B. M. Initiation and early changes in the character of the heart beat in vertebrate embryos. Physiol. Rev., 29(1):31-47, 1949.

Piegger, J.; Kovacs, P. \& Ambach, E. Extremely high origin of the right coronary artery from the ascending aorta. Clin. Anat., 5:369-72, 2001.

Poelmann, R. E.; Gittenberger-de Groot, A. C.; Mentink, M. M.; Bokenkamp, R. \& Hogers, B. Development of the cardiac coronary vascular endothelium, studied with antiendothelial antibodies, in chicken-quail chimeras. Circ. Res., 73(3):559-68, 1993.

Ratajska, A. \& Fiejka, E. Prenatal development of coronary arteries in the rat: morphologic patterns. Anat. Embryol., 200(5):533-40, 1999. 
Rothenberg, F.; Hitomi, M.; Fisher, S. A. \& Watanabe, M. Initiation of apoptosis in the developing avian outflow tract myocardium. Dev. Dyn., 223(4):469-82, 2002.

Rychter, Z. \& Ostádal, B. Mechanism of the development of coronary arteries in chick embryo. Folia Morphol., 19(2):113-24, 1971.

Tevosian, S. G.; Deconinck, A. E.; Tanaka, M.; Schinke, M.; Litovsky, S. H.; Izumo, S.; Fujiwara, Y. \& Orkin, S. H. FOG2, a cofactor for GATA transcription factors, is essential for heart morphogenesis and development of coronary vessels from epicardium. Cell, 101(7):729-39, 2000.

Tomanek, R. J. Formation of the coronary vasculature during development. Angiogenesis, 8(3):273-84, 2005.

Tomanek, R. J.; Haung, L.; Suvarna, P. R.; O'Brien, L. C.; Ratajska, A. \& Sandra, A. Coronary vascularization during development in the rat and its relationship to basic fibroblast growth factor. Cardiovasc. Res., 31:E116-126, 1996.

Tomanek, R. J.; Holifield, J. S.; Reiter, R. S.; Sandra, A. \& Lin, J. J. Role of VEGF family members and receptors in coronary vessel formation. Dev. Dyn., 225(3):233-40, 2002.

Tomanek, R. J.; Hu, N.; Phan, B. \& Clark, E. B. Rate of coronary vascularization during embryonic chicken development is influenced by the rate of myocardial growth. Cardiovasc. Res., 41(3):663-71, 1999.

Tomanek, R. J.; Ishii, Y.; Holifield, J. S.; Sjogren, C. L.; Hansen, H. K. \& Mikawa, T. VEGF family members regulate myocardial tubulogenesis and coronary artery formation in the embryo. Circ. Res., 98(7):947-53, 2006.

Tomanek, R. J. \& Zheng, W. Role of growth factors in coronary morphogenesis. Tex. Heart Inst. J., 29(4):2504, 2002.

Turner, K. \& Navaratnam, V. The positions of coronary arterial ostia. Clin. Anat., 9(6):376-80, 1996.

van den Hoff, M. J.; Kruithof, B. P.; Moorman, A. F.; Markwald, R. R. \& Wessels, A. Formation of myocardium after the initial development of the linear heart tube. Dev. Biol., 240(1):61-76, 2001.

Velkey, J. M. \& Bernanke, D. H. Apoptosis during coronary artery orifice development in the chick embryo. Anat. Rec., 262(3):310-7, 2001.
Virágh, S. \& Challice, C. E. The origin of the epicardium and the embryonic myocardial circulation in the mouse. Anat. Rec., 201(1):157-68, 1981.

Vrancken Peeters, M. P.; Gittenberger-de Groot, A. C.; Mentink, M. M.; Hungerford, J. E.; Little, C. D. \& Poelmann, R. E. The development of the coronary vessels and their differentiation into arteries and veins in the embryonic quail heart. Dev. Dyn., 208(3):338-48, 1997.

Wada, A. M.; Willet, S. G. \& Bader, D. Coronary vessel development: a unique form of vasculogenesis. Arterioscler. Thromb. Vasc. Biol., 23(12):2138-45, 2003.

Waldo, K. L.; Kumiski, D. H. \& Kirby, M. L. Association of the cardiac neural crest with development of the coronary arteries in the chick embryo. Anat. Rec., 239(3):315-31, 1994.

Waldo, K. L.; Willner, W. \& Kirby, M. L. Origin of the proximal coronary artery stems and a review of ventricular vascularization in the chick embryo. Am. J. Anat., 188(2):109-20, 1990.

\section{Correspondence to:}

Prof. Dr. Carlos Alberto Mandarim-de-Lacerda

Laboratório de Morfometria e Morfologia Cardiovascular,

Centro Biomédico, Instituto de Biologia,

Universidade do Estado do Rio de Janeiro.

Av 28 de Setembro, 87 (fds) - 20551-030

Rio de Janeiro, RJ,

BRASIL

Phone/Fax: (+55. 21) 2587-6416

E-mail: mandarim@pq.cnpq.br

URL: www.Immc.uerj.br

Received: 24-04-2009

Accepted: 22-06-2009 